\title{
Valve-sparing root replacement in patients with bicuspid versus tricuspid aortic valves
}

\author{
Maral Ouzounian, MD, PhD, Christopher M. Feindel, MD, MSc, Cedric Manlhiot, PhD, \\ Carolyn David, RN, and Tirone E. David, MD
}

\section{ABSTRACT}

Objectives: We sought to compare the outcomes of patients undergoing aortic valve-sparing root replacement with bicuspid versus tricuspid aortic valves.

Methods: A total of 333 consecutive patients (bicuspid aortic valve, $\mathrm{n}=45$; tricuspid aortic valve, $\mathrm{n}=288$ ) underwent valve-sparing root replacement using the reimplantation technique from 1988 to 2012 at a single institution. The primary analysis was performed on a 1:3 bicuspid aortic valve:tricuspid aortic valve propensity-matched dataset to mitigate known differences between these 2 groups. In the matched, dataset, mean age (bicuspid aortic valve: $40 \pm 13$ years; tricuspid aortic valve: $41 \pm 14$ ) and rates of comorbidities were similar between groups. Patients with bicuspid aortic valves were less likely to have Marfan syndrome (bicuspid aortic valve: $9 \%$ vs tricuspid aortic valve: $53 \%, P<.001)$. Patients were followed prospectively with aortic root imaging for a median of $8.2(5.3-12.2)$ years.

Results: Primary cusp repair was required more often in patients with bicuspid aortic valves (bicuspid aortic valve: $79 \%$ vs tricuspid aortic valve: $45 \%$, $P<.001$ ). A total of 3 operative deaths occurred (bicuspid aortic valve $0 \%$ vs tricuspid aortic valve $2 \%, P=.52$ ). The probability of aortic insufficiency increased significantly over time in both groups (odds ratio, 1.106; 95\% confidence interval, $1.033-1.185 ; P=.004)$, but there was no significant difference in this increase between the bicuspid aortic valve and tricuspid aortic valve groups $(P=.08)$. Long-term freedom from mortality $(P=.20)$, cumulative incidence of aortic valve reoperation $(P=.42)$, and valve-related events $(P=.69)$ were similar across groups.

Conclusions: In well-selected patients with bicuspid aortic valves and favorable cusp morphology, valve-sparing root replacement offers excellent long-term clinical outcomes. (J Thorac Cardiovasc Surg 2019;158:1-9)

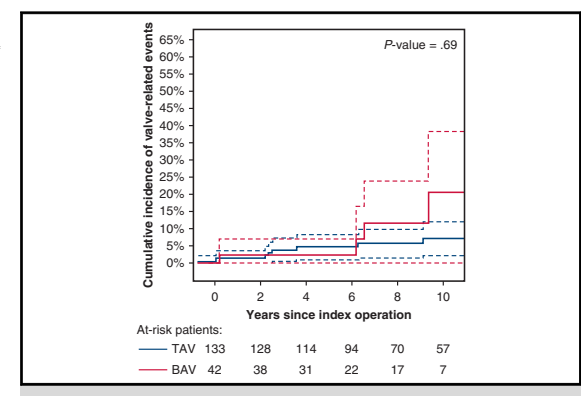

Valve-related adverse events over time in patients undergoing AVS surgery.

\section{Central Message}

In well-selected patients with BAVs, valvesparing root replacement offers excellent long-term clinical outcomes.

\section{Perspective}

Whether the outcomes after valve-sparing root replacement in patients with BAVs are similar to those with TAVs remains uncertain. This study reports long-term mortality, aortic valve reoperation, and the development of moderate to severe $\mathrm{AI}$ in patients undergoing valvesparing root replacement with BAV versus TAV

See Commentaries on pages 10 and 12.
Aortic valve-sparing (AVS) operations have proven to be a durable strategy in patients with aortic aneurysms and favorable cusp morphology ${ }^{1,2}$ and are associated with improved long-term outcomes when compared with

\footnotetext{
From the Division of Cardiovascular Surgery, Peter Munk Cardiac Centre, Toronto General Hospital, Department of Surgery, University of Toronto, Toronto, Canada. Research Ethics Board: University Health Network Research Ethics Board \#06-0756 October 31, 2014.

Read at the 97th Annual Meeting of The American Association for Thoracic Surgery, Boston, Massachusetts, April 29-May 3, 2017.

Received for publication July 7, 2017; revisions received Aug 28, 2018; accepted for publication Oct 4, 2018.

Address for reprints: Maral Ouzounian, MD, PhD, Toronto General Hospital, 200 Elizabeth St, 4N-464, Toronto, ON M5G2C4, Canada (E-mail: maral, ouzounian@uhn.ca).

$0022-5223 / \$ 36.00$

Copyright (c) 2018 by The American Association for Thoracic Surgery https://doi.org/10.1016/j.jtcvs.2018.10.151
}

valve-replacing root procedures. ${ }^{3}$ Initially designed for morphologically normal tricuspid aortic valves (TAVs), over the years, AVS techniques have been extended to include patients with cusp prolapse, severe aortic insufficiency (AI), bicuspid aortic valves (BAVs), and acute aortic dissections.

$\square$ Scanning this QR code will
take you to the article title
page to access supplementary
information. To view the
AATS Annual Meeting Web-
cast, see the URL next to the
webcast thumbnail.




\section{Abbreviations and Acronyms \\ $\mathrm{AI}=$ aortic insufficiency \\ AVS $=$ aortic valve sparing \\ $\mathrm{BAV}=$ bicuspid aortic valve \\ $\mathrm{TAV}=$ tricuspid aortic valve}

Whereas the AI associated with aortic root aneurysms and TAV is often due to dilatation of the ventriculoaortic and sinotubular junctions, the mechanism of the $\mathrm{AI}$ in patients with BAV and root aneurysms often results from a combination of dilatation and distortion of root geometry along with primary cusp pathology. Although several groups have reported excellent results with AVS in patients with $\mathrm{BAV},{ }^{4,5}$ long-term comparative data are lacking. The purpose of the current study was to compare the outcomes of patients undergoing AVS with BAV versus TAV. We hypothesized there would be no difference in the need for aortic valve replacement or recurrent significant AI for patients with BAV root aneurysms undergoing AVS compared with those with TAV.

\section{MATERIALS AND METHODS \\ Study Population}

Of the 408 patients who underwent AVS surgery between 1988 and 2012 for aortic root aneurysms at the Peter Munk Cardiac Centre, only patients for whom the reimplantation technique was used $(\mathrm{N}=333)$ were included in this study. A total of 45 patients had BAV, and 288 patients had TAV. Patients who underwent valve-sparing root replacement between 1990 and 2012 represented $25 \%$ of all patients undergoing root replacement at our institution. In contrast, among patients with BAV, only $7 \%$ of those who underwent root replacement had a valve-sparing approach. Patients were followed prospectively with annual echocardiographic studies during the first decade and every 2 to 3 years thereafter if the aortic valve function had remained stable. For the present report, the follow-up period was closed on September 30, 2015. The median (interquartile range) follow-up duration was 8.2 (5.3-12.2) years with some differences between groups (TAV: 8.4 [5.6-12.6] years vs BAV: 5.6 [3.3-9.6] years; $P=.06$ ). The clinical follow-up data were complete in all patients, and specific dates of events were available for all outcomes. A total of 1334 echocardiographic studies were available for analysis (median 4 studies per patient). Echocardiographic studies were available in $98 \%$ of patients without terminal events during the most recent 3 years. The Research Ethics Board of the University Health Network approved the study (Research Ethics Board \#06-0756) and waived the need for individual patient consent.

\section{Statistical Analyses}

For the descriptive analysis, clinical characteristics were summarized in terms of means \pm standard deviation or medians (interquartile ranges) for continuous variable and frequencies for dichotomous and polytomous variables. Between-group differences in continuous variables were assessed using Wilcoxon rank-sum tests, and differences in dichotomous/polytomous variables were assessed using Fisher exact tests.

For propensity score matching, logistic regression was used to derive a propensity score for belonging to the BAV versus the TAV group. The variables included in the regression model (a priori selection) were age, sex,
New York Heart Association grade, left ventricle grade, and reoperation. Propensity score matching in a 1:3 ratio of BAV:TAV subjects was performed using a greedy algorithm without replacement with a maximum allowable difference in propensity score within pairs of 0.03 . Additional controls for cases who were not fully matched using this algorithm were selected using nearest neighbors without replacement.

For the time-to-event analysis, the primary outcome of interest was mortality, and freedom from mortality was estimated using the Kaplan-Meier survival method. Secondary outcomes of interest included (1) reoperation on the aortic valve; (2) moderate to severe AI (AI >2.5); and (3) valverelated adverse event: a composite of valve-related death, reoperation of the aortic valve, thromboembolism, anticoagulant-related hemorrhage requiring blood transfusion or resulting in stroke or death, and endocarditis. All-cause mortality and cause of death were determined by review of patients' medical records and death certificates. In accordance with the valve-reporting guidelines, ${ }^{6}$ we defined valve-related mortality as any death caused by structural or nonstructural valve deterioration, valve thrombosis, embolism, bleeding event, or endocarditis; death related to reintervention on the operated valve; or sudden, unexplained death.

Cumulative incidence of valve reoperation was calculated using allcause death as a competing risk. Cumulative incidence of valve-related events was calculated using nonvalve-related death as the competing risk. Between-group differences were assessed using the log-rank test for freedom from mortality and Gray's test for cumulative incidence estimates. The predicted probability of moderate to severe AI over time was estimated using a logistic regression adjusted for repeated measures using an autoregressive correlation structure. All statistical analyses were performed using SAS v9.4 (SAS Institute Inc, Cary NC) and R (v3.4).

\section{RESULTS \\ Baseline Characteristics}

The baseline characteristics of the final propensitymatched set are shown in Table 1. After 1:3 propensitymatching, the mean age of the set was $41 \pm 14$ years, and $160(89 \%)$ were male. Most patients undergoing AVS had preserved heart function and were undergoing elective surgery. Patients with BAV were less likely to have Marfan syndrome (BAV: $9 \%$ vs TAV: $53 \%, P<.001$ ) than those with TAV.

\section{Operative Details and Perioperative Outcomes}

Among patients with BAV, the majority $(82 \%)$ had Sievers type 1 valves, and $18 \%$ had type 0 valves. Operative details are summarized in Table 2. Primary cusp repair was required more often in patients with BAV $(79 \%$ vs $45 \%, P<.001)$. Specifically, more patients with BAV required cusp plication (BAV: $76 \%$ vs TAV: $35 \%$, $P<.001$ ), whereas reinforcement of the free margin with polytetrafluoroethylene (Gore-Tex, WL Gore \& Associates, Inc, Flagstaff, Ariz) suture was similar between groups (BAV: $25 \%$ vs TAV: $28 \%, P=.84$ ). The most common diameter of the graft used in each group was 34. Among patients with BAV, $33 \%$ underwent raphe resection and $13 \%$ were noted to have mild calcification of the cusps. No patients with BAV had greater than mild calcification or underwent patch repair of the cusps. 
TABLE 1. Baseline characteristics of patients undergoing aortic valve-sparing surgery

\begin{tabular}{|c|c|c|c|c|c|}
\hline Variable & & $\frac{\text { TAV }}{(\mathbf{N}=\mathbf{1 3 5})}$ & & $\frac{\text { BAV }}{(N=45)}$ & $P$ value \\
\hline Age, y (range) & 135 & $41 \pm 14$ & 45 & $40 \pm 13$ & .93 \\
\hline Male, $\%$ & 135 & $121(90)$ & 45 & $39(87)$ & .59 \\
\hline Urgent or emergency, $\%$ & 135 & $4(3)$ & 45 & $1(2)$ & 1.00 \\
\hline Any previous cardiac surgery, $\%$ & 135 & $8(6)$ & 45 & $3(7)$ & 1.00 \\
\hline \multicolumn{6}{|l|}{ Clinical presentation } \\
\hline Angina (all stable), \% & 135 & $4(3)$ & 45 & $2(4)$ & .64 \\
\hline Heart failure, $\%$ & 135 & $5(4)$ & 45 & $0(0)$ & .33 \\
\hline Shock, $\%$ & 135 & $0(0)$ & 45 & $0(0)$ & 1.00 \\
\hline Syncope, $\%$ & 135 & $2(1)$ & 45 & $1(2)$ & 1.00 \\
\hline New York Heart Association class & 135 & & 45 & & .49 \\
\hline I, $\%$ & & $109(81)$ & & $33(73)$ & \\
\hline II, \% & & $22(16)$ & & $12(27)$ & \\
\hline III, \% & & $3(2)$ & & $0(0)$ & \\
\hline IV, \% & & $1(1)$ & & $0(0)$ & \\
\hline Left ventricular ejection fraction & 135 & & 45 & & .33 \\
\hline$>60 \%, \%$ & & $105(78)$ & & $30(67)$ & \\
\hline $40 \%-59 \%, \%$ & & $21(16)$ & & $10(22)$ & \\
\hline $20 \%-39 \%, \%$ & & $9(7)$ & & $5(11)$ & \\
\hline$<20 \%, \%$ & & $0(0.0)$ & & $0(0.0)$ & \\
\hline \multicolumn{6}{|l|}{ Associated disease } \\
\hline Marfan syndrome, $\%$ & 135 & $71(53)$ & 45 & $4(9)$ & $<.001$ \\
\hline Diabetes, $\%$ & 135 & $1(1)$ & 45 & $1(2)$ & .44 \\
\hline Hypertension, \% & 135 & $42(31)$ & 45 & $13(29)$ & .85 \\
\hline Hyperlipidemia, \% & 135 & $16(12)$ & 45 & $8(18)$ & .32 \\
\hline Renal failure, $\%$ & 135 & $0(0)$ & 45 & $0(0)$ & - \\
\hline Smoking history, $\%$ & 135 & $56(41)$ & 45 & $16(36)$ & .60 \\
\hline Chronic obstructive pulmonary disease, $\%$ & 135 & $2(1)$ & 45 & $1(2)$ & 1 \\
\hline Previous stroke or transient ischemic attack, $\%$ & 135 & $4(3)$ & 45 & $3(7)$ & .44 \\
\hline \multicolumn{6}{|l|}{ Preoperative findings } \\
\hline Aortic root diameter, $\mathrm{mm}$ & 112 & $54 \pm 5$ & 39 & $52 \pm 8$ & .24 \\
\hline Aortic regurgitation (greater than mild), $\%$ & 135 & $83(61)$ & 45 & $35(78)$ & .03 \\
\hline Mitral regurgitation (greater than mild), $\%$ & 135 & $7(5)$ & 45 & $2(4)$ & 1.00 \\
\hline
\end{tabular}

$T A V$, Tricuspid aortic valve; $B A V$, bicuspid aortic valve.

A greater proportion of patients with BAV underwent concomitant aortic arch replacement (BAV: $11 \%$ vs TAV: $6 \%, P=.002$ ). Three operative deaths occurred (BAV $0 \%$ vs TAV $2 \%, P=.57$ ). The frequency of all early complications was low and similar between the 2 groups (Table 3).

\section{Long-Term Outcomes}

The unadjusted long-term outcomes of interest stratified by valve morphology are reported in Table 4 . Table 4 reports the freedom from death and the cumulative incidence rates for the other outcomes of interest at 1,5 , and 10 years. There was no significant difference in freedom from death between the 2 groups $(P=.20)$ (Figure 1).
During the follow-up periods, 2 patients (BAV: 1, TAV: 1) underwent aortic valve reoperations (Table 4 and Figure 2), and 5 patients (BAV 2, TAV: 3 ) developed moderate to severe AI (Table 4). There were no differences in the cumulative incidence of aortic valve reoperations $(P=.42)$ or valve-related adverse events $(P=.69)$ (Figure 3 ) between patients with BAV and TAV. The probability of AI increased significantly over time in both groups (odds ratio, 1.106; $95 \%$ confidence interval, $1.033-1.185 ; P=.004$ ), but there was no significant difference in this increase between patients with BAV and TAV $(P=.08)$. There was no statistically significant difference in the effect of time on postprocedure AI between the BAV and TAV groups $(P=.085)$. Similar results were obtained when the analysis was performed on the entire cohort $(\mathrm{N}=333)$. 
TABLE 2. Intraoperative details

\begin{tabular}{|c|c|c|c|c|c|}
\hline Variable & & $\frac{\text { TAV }}{(\mathbf{N}=\mathbf{1 3 5})}$ & & $\frac{\text { BAV }}{(\mathbf{N}=\mathbf{3 5})}$ & $P$ value \\
\hline Size of aortic Dacron graft prosthesis & 135 & & 45 & & \\
\hline Mean $(\mathrm{mm}), \pm \mathrm{SD}$ & & $31 \pm 2$ & & $31 \pm 3$ & .93 \\
\hline Median (IQR) (mm) & & $32(30-34)$ & & $32(30-34)$ & \\
\hline Any cusp repaired,* \% & 132 & $59(45)$ & 42 & $33(79)$ & $<.001$ \\
\hline Any cusp plication, $\%$ & 130 & $46(35)$ & 42 & $32(76)$ & $<.001$ \\
\hline No. of cusps shortened by plication & 130 & & 42 & & $<.001$ \\
\hline 0 & & $84(65)$ & & $10(24)$ & \\
\hline 1 & & $20(15)$ & & $16(38)$ & \\
\hline 2 & & $19(15)$ & & $16(38)$ & \\
\hline 3 & & $7(5)$ & & & \\
\hline $\begin{array}{l}\text { Any cusp reinforced with polytetrafluoroethylene \% } \\
\text { (Gore-Tex, WL Gore \& Associates, Flagstaff, Ariz) }\end{array}$ & 131 & $37(28)$ & 40 & $10(25)$ & .84 \\
\hline No. of cusps reinforced with Gore-Tex & 131 & & 40 & & .12 \\
\hline 0 & & $94(72)$ & & $30(75)$ & \\
\hline 1 & & $32(24)$ & & $6(15)$ & \\
\hline 2 & & $3(2)$ & & $4(10)$ & \\
\hline 3 & & $2(2)$ & & $0(0)$ & \\
\hline Any neosinus created, $\%$ & 123 & $72(59)$ & 32 & $15(47)$ & .32 \\
\hline No. of neoaortic sinuses created & 123 & & 32 & & .007 \\
\hline 0 & & $51(41)$ & & $17(53)$ & \\
\hline 1 & & $52(42)$ & & $10(31)$ & \\
\hline 2 & & $0(0)$ & & $3(9)$ & \\
\hline 3 & & $20(16)$ & & $2(6)$ & \\
\hline Aortic arch replacement, $\%$ & 133 & $8(6)$ & 39 & $5(13)$ & .002 \\
\hline Coronary artery bypass grafting, $\%$ & 135 & $10(7)$ & 45 & $1(2)$ & .3 \\
\hline Mitral valve repair, \% & 135 & $7(5)$ & 45 & $2(4)$ & 1.00 \\
\hline Repair of congenital defect & 135 & $14(10)$ & 45 & $2(4)$ & .36 \\
\hline Cardiopulmonary bypass time $(\mathrm{min}), \pm \mathrm{SD}$ & 135 & $134 \pm 24$ & 45 & $139 \pm 35$ & .32 \\
\hline Crossclamp time (min), \pm SD & 135 & $111 \pm 20$ & 45 & $116 \pm 28$ & .28 \\
\hline Body surface area $\left(\mathrm{m}^{2}\right)$ & 135 & $2.1 \pm 0.2$ & 45 & $2.1 \pm 0.3$ & .84 \\
\hline
\end{tabular}

$\overline{T A V}$, Tricuspid aortic valve; $B A V$, bicuspid aortic valve; $S D$, standard deviation; $I Q R$, interquartile range. *Repair includes plication or reinforcement with polytetrafluoroethylene (Gore-Tex).

\section{DISCUSSION}

Several groups have demonstrated excellent long-term results with AVS operations, ${ }^{2,7,8}$ which are an attractive option for patients presenting with an aortic root aneurysm with or without AI. In this study, we observed no significant early or long-term differences between patients with BAV undergoing AVS (Video 1) and patients with TAV. Specifically, patients with BAV experienced similar long-term freedom from death, aortic valve reoperation, and moderate or severe AI than those with TAV undergoing AVS.

Bicuspid valve disease presents with a wide range of morphologic configurations of the cusps, sinuses, commissures, and associated aortopathy. ${ }^{9,10}$ Heterogeneity is also observed in the mechanism of BAV AI, which may be due to a restrictive or calcified conjoint cusp, cusp prolapse or fenestrations, a severely dilated annulus, or a combination of these. BAV repair strategies must address each of the pathologic components in an effort to restore functional root geometry and may include free-margin plication, raphe resection or shaving, free margin resuspension, and various techniques of annular downsizing. Adoption of valvesparing root replacement in the context of BAV has been increasingly undertaken with excellent long-term results. ${ }^{4,511}$ Particularly for the young patient, the benefits of valve preservation, with low rates of endocarditis and thrombo-hemorrhagic events are undeniable. However, $\mathrm{BAV}$ repair has been accompanied by a considerable rate of recurrent and progressive AI. In a series of 108 consecutive patients undergoing isolated BAV repair without AVS, the need for reoperation was reported to be as high as $51 \%$ 
TABLE 3. Early outcomes

\begin{tabular}{lcccc}
\hline \multicolumn{1}{c}{ Variable } & TAV & BAV & \\
\cline { 2 - 3 } & $(\mathbf{N}=\mathbf{1 3 5})$ & $(\mathbf{N}=\mathbf{4 5})$ & $\boldsymbol{P}$ value \\
\hline Mortality, \% & $3(2)$ & $0(0 \%)$ & .57 \\
$\begin{array}{l}\text { Reoperation for bleeding, \% } \\
\begin{array}{l}\text { Perioperative myocardial } \\
\text { infarction, \% }\end{array}\end{array}$ & $9(7)$ & $3(7)$ & 1.00 \\
$\begin{array}{l}\text { Insertion of intra-aortic } \\
\text { balloon pump, \% }\end{array}$ & $1(1)$ & $2(4)$ & .06 \\
$\begin{array}{l}\text { Insertion of permanent } \\
\text { pacemaker, \% }\end{array}$ & $1(1)$ & $1(2)$ & .44 \\
$\begin{array}{l}\text { Postoperative atrial } \\
\quad \text { fibrillation, \% }\end{array}$ & $24(18)$ & $10(22)$ & .51 \\
\hline $\begin{array}{l}\text { Stroke or transient ischemic } \\
\text { attack, \% }\end{array}$ & $1(1)$ & $1(2)$ & .44 \\
\hline $\begin{array}{l}\text { Sternal wound infection, \% } \\
\text { Sepsis, \% }\end{array}$ & $1(1)$ & $0(0)$ & 1.00 \\
\hline
\end{tabular}

$T A V$, Tricuspid aortic valve; $B A V$, bicuspid aortic valve.

after 10 years. ${ }^{12}$ Svensson and colleagues ${ }^{13}$ observed that of 728 patients who underwent BAV repair using a variety of techniques, $25 \%$ of patients had moderate $\mathrm{AI}$ and $24 \%$ had severe AI by 5 years of follow-up.

Several predictors of failure have been identified in BAV repair. In a study of 357 patients who underwent BAV repair

TABLE 4. Long-term outcomes

\begin{tabular}{|c|c|c|c|}
\hline Variable & $\begin{array}{c}\text { TAV } \\
(\mathbf{n}=\mathbf{1 3 5})\end{array}$ & $\begin{array}{c}\text { BAV } \\
(n=45)\end{array}$ & $\begin{array}{c}P \\
\text { value }\end{array}$ \\
\hline \multicolumn{4}{|l|}{$\begin{array}{l}\text { Freedom from } \\
\text { mortality, } \%\end{array}$} \\
\hline $1 \mathrm{y}$ & $99.2 \%(94.8-99.9)$ & $100 \%$ & .20 \\
\hline $5 \mathrm{y}$ & $99.2 \%(94.8-99.9)$ & $100 \%$ & \\
\hline $10 \mathrm{y}$ & $94.1 \%(85.9-97.6)$ & $100 \%$ & \\
\hline \multicolumn{4}{|l|}{$\begin{array}{l}\text { Cumulative } \% \text { of } \\
\text { AI }>2.5\end{array}$} \\
\hline $1 \mathrm{y}$ & $0.8 \%(0.3-2.3)$ & $2.7 \%(1.1-6.8)$ & .08 \\
\hline $5 \mathrm{y}$ & $1.2 \%(0.5-2.9)$ & $3.9 \%(1.5-9.9)$ & \\
\hline $10 \mathrm{y}$ & $1.9 \%(0.8-4.3)$ & $6.5 \%(2.1-18.3)$ & \\
\hline \multicolumn{4}{|c|}{$\begin{array}{l}\text { Cumulative } \% \text { of aortic } \\
\text { valve reoperation }\end{array}$} \\
\hline $1 \mathrm{y}$ & 0 & 0 & .42 \\
\hline $5 y$ & 0 & 0 & \\
\hline $10 \mathrm{y}$ & $1.4 \%(0.0-4.2)$ & $4.2 \%(0.0-11.8)$ & \\
\hline \multicolumn{4}{|c|}{$\begin{array}{l}\text { Cumulative } \% \text { of } \\
\text { valve-related events }\end{array}$} \\
\hline $1 \mathrm{y}$ & $1.5 \%(0.0-3.6)$ & $2.4 \%(0.0-6.9)$ & .69 \\
\hline $5 \mathrm{y}$ & $4.7 \%(1.0-8.3)$ & $2.4 \%(0.0-6.9)$ & \\
\hline $10 \mathrm{y}$ & $7.2 \%(2.1-12.0)$ & $20.5 \%(0.0-38.3)$ & \\
\hline
\end{tabular}

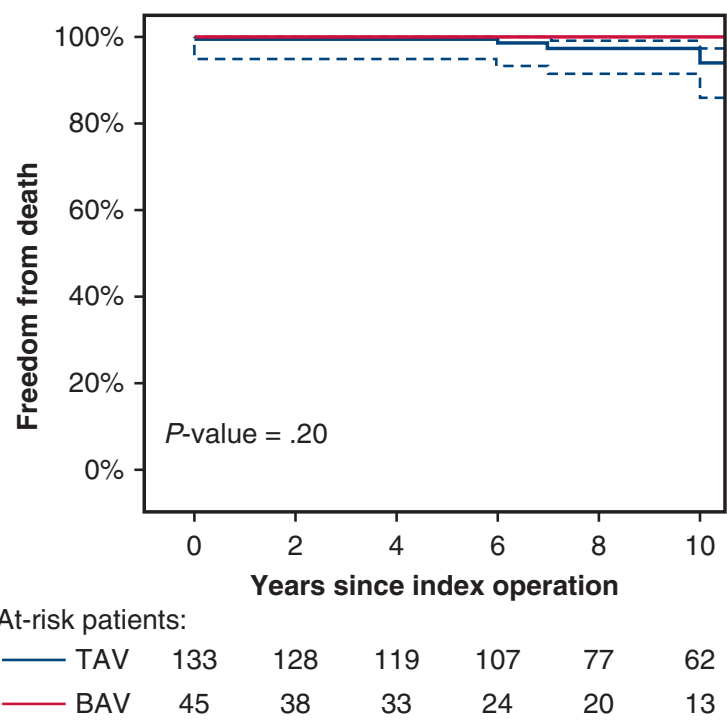

FIGURE 1. Freedom from death in patients undergoing AVS surgery. Freedom from death was estimated using the Kaplan-Meier method, and differences were assessed with log-rank tests. There was no significant difference in mortality across the 2 groups $(P=.20)$. TAV, Tricuspid aortic valve; $B A V$, bicuspid aortic valve.

and root remodeling, cusp calcification and cusp reconstruction with a pericardial patch were the strongest predictors of failure. ${ }^{4}$ The number and location of raphes and the extent of their fusion may affect the late success of BAV

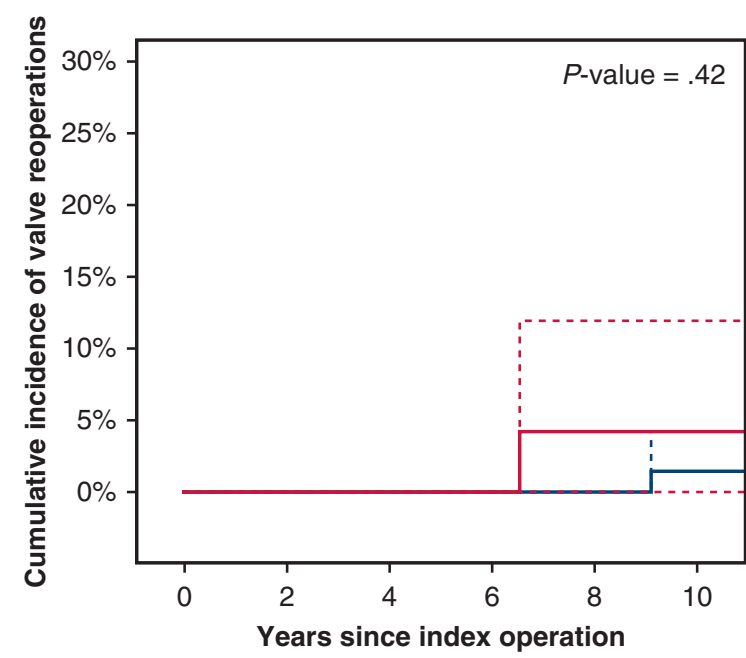

At-risk patients:

$\begin{array}{lcccccc}\text { TAV } & 134 & 129 & 118 & 97 & 73 & 58 \\ \text { BAV } & 45 & 39 & 33 & 25 & 19 & 10\end{array}$

FIGURE 2. Aortic valve reoperation over time in patients undergoing AVS surgery. The cumulative incidence of patients with aortic valve reoperation was summarized. Gray's test was applied to assess differences between cohorts. There was no significant difference in cumulative incidence rates of aortic valve reoperation in patients with BAV compared with TAV $(P=.42) . T A V$, Tricuspid aortic valve; $B A V$, bicuspid aortic valve. 


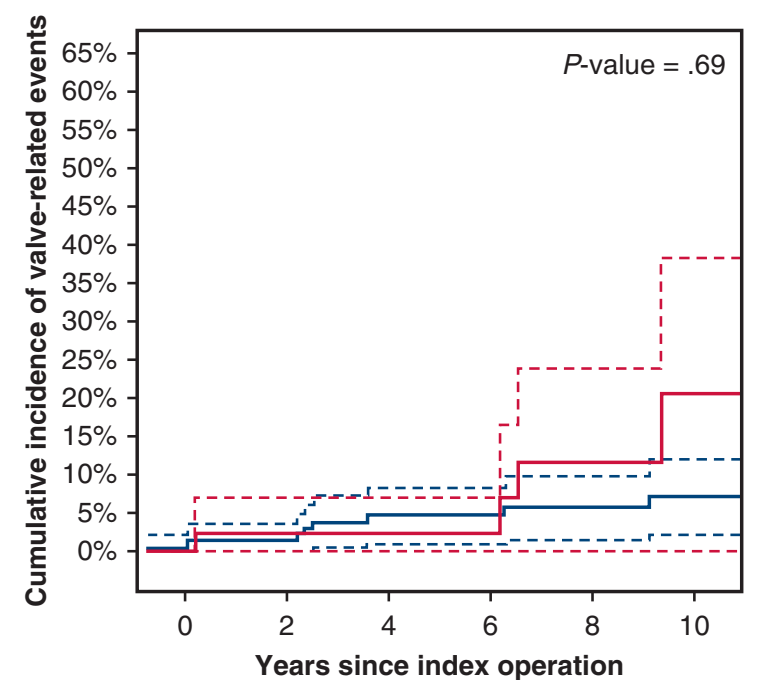

At-risk patients:

$\begin{array}{lcccccc}\text { TAV } & 133 & 128 & 114 & 94 & 70 & 57 \\ \text { BAV } & 42 & 38 & 31 & 22 & 17 & 7\end{array}$

FIGURE 3. Valve-related adverse events over time in patients undergoing AVS surgery. The cumulative incidence of patients with valve-related adverse events was summarized. Gray's test was applied to assess differences between cohorts. There was no significant difference in cumulative incidence rates of valve-related adverse events in patients with BAV compared with TAV $(P=.69)$. TAV, Tricuspid aortic valve; $B A V$, bicuspid aortic valve.

repair, and valves with larger angles and complete cusp fusion have been linked to favorable outcomes. ${ }^{14,15}$ Finally, several groups have suggested that a root replacement procedure rather than subcommissural plication increases the durability of BAV repair, particularly in patients with a dilated annulus. ${ }^{11,14,16,17}$

Our results add to previous reports that demonstrate the long-term durability of AVS for patients with BAV. The heterogeneity of patients with BAV, the repair techniques used, and the variable length and completeness of follow-up make

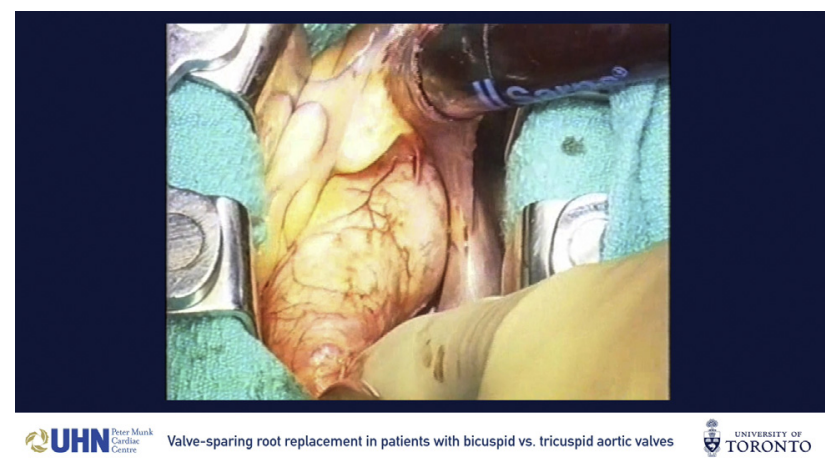

VIDEO 1. Valve-sparing root replacement with reimplantation technique in a patient with BAV. Video available at: https://www.jtcvs.org/article/ S0022-5223(18)33143-X/fulltext. interpretation of the literature challenging. We have adopted a highly selective policy for choosing which BAVs to repair, avoiding valves that are calcified, have restricted cusp motion, or require patch augmentation or replacement of a cusp. In patients with aortic root aneurysms, we continue to favor reimplantation of the valve to ensure long-term stability of the ventriculoaortic junction.

\section{Study Limitations}

The main limitations of this study are its retrospective nature and the sample size with relatively few patients with BAV compared with TAV. There is inherent bias in which patients are selected and who are denied a valve-sparing operation, particularly in the context of BAV. Patients with calcified or restrictive leaflets requiring resection or leaflet augmentation were usually deemed ineligible for AVS. We acknowledge that because 2 expert aortic surgeons performed the majority of the root procedures in this highly selected patient population, these data may not be generalizable.

\section{CONCLUSIONS}

Although patients with BAV require more concomitant cusp repair, valve-sparing root replacement offers excellent long-term clinical outcomes in carefully selected patients with both BAV and TAV who require root replacement.

\section{Webcast}

You can watch a Webcast of this AATS meeting presentation by going to: https://aats.blob.core.windows.net/ media/17AM/2017-05-02/RM311/05-02-17_Room311_ 1651_Ouzounian.mp4.

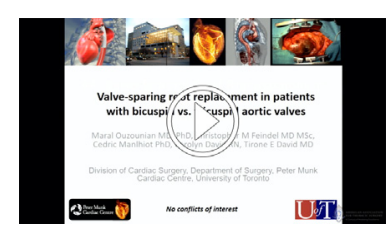

\section{Conflict of Interest Statement}

Authors have nothing to disclose with regard to commercial support.

The authors thank Dr Myriam Lafreniere-Roula and Dr Steve Chun-Po Fan for statistical support.

\section{References}

1. David TE, David CM, Manlhiot C, Colman J, Crean AM, Bradley T. Outcomes of aortic valve-sparing operations in Marfan syndrome. J Am Coll Cardiol. 2015;66: 1445-53.

2. David TE, Feindel CM, David CM, Manlhiot C. A quarter of a century of experience with aortic valve-sparing operations. J Thorac Cardiovasc Surg. 2014;148: $872-80$. 
3. Ouzounian M, Rao V, Manlhiot C, Abraham N, David C, Feindel CM, et al. Valve-sparing root replacement compared with composite valve graft procedures in patients with aortic root dilation. J Am Coll Cardiol. 2016;68:1838-47.

4. Schneider U, Feldner SK, Hofmann C, Schope J, Wagenpfeil S, Giebels C, et al. Two decades of experience with root remodeling and valve repair for bicuspid aortic valves. J Thorac Cardiovasc Surg. 2017;153:S65-71.

5. Boodhwani M, de Kerchove L, Glineur D, Rubay J, Vanoverschelde JL, Noirhomme P, et al. Repair of regurgitant bicuspid aortic valves: a systematic approach. J Thorac Cardiovasc Surg. 2010;140:276-84.e1.

6. Akins CW, Travis B, Yoganathan AP. Energy loss for evaluating heart valve performance. J Thorac Cardiovasc Surg. 2008;136:820-33.

7. Cameron DE, Alejo DE, Patel ND, Nwakanma LU, Weiss ES, Vricella LA, et al. Aortic root replacement in 372 Marfan patients: evolution of operative repair over 30 years. Ann Thorac Surg. 2009;87:1344-9.

8. Kvitting JP, Kari FA, Fischbein MP, Liang DH, Beraud AS, Stephens EH, et al. David valve-sparing aortic root replacement: equivalent mid-term outcome for different valve types with or without connective tissue disorder. J Thorac Cardiovasc Surg. 2013;145:117-26, 127.e1-5.

9. Sievers HH, Schmidtke C. A classification system for the bicuspid aortic valve from 304 surgical specimens. J Thorac Cardiovasc Surg. 2007;133: 1226-33.

10. Fazel SS, Mallidi HR, Lee RS, Sheehan MP, Liang D, Fleischman D, et al. The aortopathy of bicuspid aortic valve disease has distinctive patterns and usually involves the transverse aortic arch. J Thorac Cardiovasc Surg. 2008;135: 901-7, 907.e1-2.

11. Kari FA, Liang DH, Kvitting JP, Stephens EH, Mitchell RS, Fischbein MP, et al. Tirone David valve-sparing aortic root replacement and cusp repair for bicuspid aortic valve disease. J Thorac Cardiovasc Surg. 2013;145:S35-40. e1-2.

12. Ashikhmina E, Sundt TM III, Dearani JA, Connolly HM, Li Z, Schaff HV. Repair of the bicuspid aortic valve: a viable alternative to replacement with a bioprosthesis. J Thorac Cardiovasc Surg. 2010;139: $1395-401$

13. Svensson LG, Al Kindi AH, Vivacqua A, Pettersson GB, Gillinov AM, Mihaljevic T, et al. Long-term durability of bicuspid aortic valve repair. Ann Thorac Surg. 2014;97:1539-47.

14. Aicher D, Kunihara T, Abou Issa O, Brittner B, Graber S, Schafers HJ. Valve configuration determines long-term results after repair of the bicuspid aortic valve. Circulation. 2011;123:178-85.

15. Kari FA, Kvitting JP, Stephens EH, Liang DH, Merk DR, Fischbein MP, et al. Tirone David procedure for bicuspid aortic valve disease: impact of root geometry and valve type on mid-term outcomes. Interact Cardiovasc Thorac Surg. 2014; 19:375-81.

16. Bavaria JE, Desai N, Szeto WY, Komlo C, Rhode T, Wallen T, et al. Valvesparing root reimplantation and leaflet repair in a bicuspid aortic valve: comparison with the 3-cusp David procedure. J Thorac Cardiovasc Surg. 2015;149: S22-8.

17. de Kerchove L, Boodhwani M, Glineur D, Vandyck M, Vanoverschelde JL, Noirhomme P, et al. Valve sparing-root replacement with the reimplantation technique to increase the durability of bicuspid aortic valve repair. J Thorac Cardiovasc Surg. 2011;142:1430-8.

Key Words: aneurysm, aortic root, aortic valve repair, bicuspid aortic valve

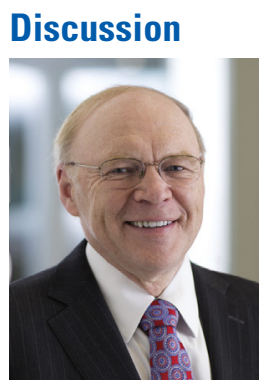

Dr Lars G. Svensson (Cleveland, Ohio). Maral, that is a wonderful report and your team has certainly led the efforts in this area. I would like to separate out your procedures, though, because I think many of us have believed that remodeling is the operation of choice for patients with bicuspid valves, but increasingly we are using reimplantation in the patients with bicuspid valves. You also point out in your manuscript that you were highly selective in using reimplantation for patients with bicuspid valves. We have done the same; our ratios are about the same. As of the end of March we have done 677 reimplantations of which 102 were bicuspid valves, so a low rate versus remodeling, and in our series there have been overall 3 deaths, and for elective procedures in 617 patients, 1 death, so a very safe operation.

I have a couple of questions for you. In the paper there was maybe a contradiction between what you said in the paper and your tables. Our general rule, as Craig Miller has pointed out to us, is using a bigger graft in the bicuspid valves; we will go out to a 32, 34 graft. Unless there is an error in your paper, the text section, it looks like you should have switched that, that you used in fact a bigger graft in your bicuspid valves. That's the first question.

And the other interesting reference in your paper is that your mean size of the aorta with bicuspid valves was 5.2 $\mathrm{cm} \pm 8 \mathrm{~mm}$. So, can you just talk a bit about your procedure when it comes to your choice of graft and the type of patients you are putting it into, for the reimplantation group of procedures?

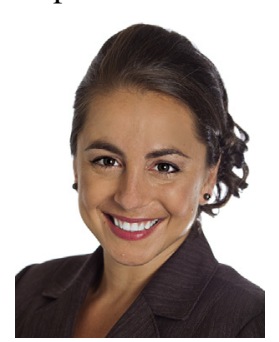

Dr Maral Ouzounian (Toronto, Ontario, Canada). Thank you very much, Dr Svensson, and thank you for discussing the paper. We have been, as you said, very selective in who gets a valve-sparing operation in patients with bicuspid aortic valves. We have done isolated bicuspid valve repair at our institution, but anyone with even moderate root dilatation, and particularly those with annuloaortic ectasia, so an annulus, anything really above $26,27 \mathrm{~mm}$, we favor reimplantation to stabilize the annulus long-term.

The graft sizing has been written about extensively, and with Dr David, there is a whole bunch of formulas with calculations, and it ends up being more of an art form than an eyeball choice, truthfully, than an actual calculation. But the graft sizes were and do tend to be slightly larger in patients with bicuspid valves.

Dr Svensson. So it sounds like you are following a bit what Mike Borger wrote about when he was with Tirone that $4.5 \mathrm{~cm}$ and bigger you will replace the root.

Another question is your repair technique for the actual leaflets. In $77 \%$ of the patients with bicuspid valves you did plications, and obviously that is the asymmetric values, usually, but you used a running suture on the leaflet edge in one quarter. I would like to hear you comment a bit more about that. Tirone has talked about it. I am increasingly convinced that in bicuspid valves we probably should be doing that more often, in other words, using a running suture on that leading edge, because I think over time some of the failures we have seen with bicuspid valve repairs is that the 
leaflets stretch; even if you have a perfect symmetrical result, over time those leaflets will still stretch. Increasingly, I am using a running leaflet edge stitch for bicuspid valve repairs. Any comments about that?

Dr Ouzounian. Initially examining the leaflet, about a third of the patients had their raphe resected or shaved off. If it was thick and fibrous or even a little bit calcified, it would be resected and then either primarily repairednone of these patients had a patch, they were mostly primarily repaired - or just shaved off.

And then we favor plication. The patients who had a running stitch rather than plication were more patients with fenestrations along the commissures. But your point is an interesting one. I think that may potentially be a factor for late durability.

Dr Svensson. One other final comment and question for you to comment on is that you had 47 patients with bicuspid valves, not all of those, I presume, were reimplantations, and the failure rates if you look at moderate severe aortic insufficiency and reoperations at 10 years is $18.8 \%$, if you combine those. Although you say there is no difference, you may not have had statistical power to show the difference, and the 2 graphs you show have a divergence between the bicuspid valves and the tricuspid valves, and this is a very long series. Over time, what have you done to try and make your bicuspid valve repairs last better after reimplantation?

The reason why I ask that is because it is going to be a very different reoperation to do for a redo reimplantation than it is going to be for a patient who has had a remodeling or, for that matter, if a patient doesn't have a root procedure, just a bicuspid valve repair.

Dr Ouzounian. Thank you. Excellent comment. Only 2 of the patients among the 47 had remodeling, and those 2 had a smaller annulus and they were older patients, and interestingly, neither of those 2 had any of the failures, neither of those 2 were in the failure group.

Over time we have changed a few things that we have done. One is to be more aggressive with leaflet repair in general, so more plication over time has happened. Dr David now also uses Dr Gleason's described technique of actually detaching the fused cusps from the aortic annulus and moving it down to the right ventricular outflow tract with a pericardial patch, which is not at the leaflet edge but rather on the inner surface at the base of the leaflet. We will see how those techniques evolve.

Dr Svensson. Congratulations on a great paper.

Dr Malakh Lal Shrestha (Hannover, Germany). In the $77 \%$ of the patients where you did the leaflet plasty, did you see any stenosis in follow-up?

Dr Ouzounian. No. We have not seen anyone come back for a stenotic valve. I can't comment exactly on the gradients over time, we haven't look at that, but that is an interesting point.

Dr Michael A. Borger (Leipzig, Germany). Is calcium on the aortic valve cusps a contraindication?

Dr Ouzounian. We have been quite selective. So a little bit of calcium that we can shave off we will, but a heavy amount of calcification that makes a leaflet immobile, we would replace those valves.

Dr Joseph S. Coselli (Houston, Tex). Maral, a great presentation. You have shown us some of your other studies that the patients who undergo remodeling with Marfan syndrome have had a much worse outcome. You have a very high percentage of Marfan in your tricuspid and the usual in the bicuspid. Since you know that those were possibly at much higher risk of failure, did you think about pulling those out of the analysis to compare them?

And the second question is, you showed a difference between the bicuspid and tricuspid, and you mentioned that one of the possible differences is age. You can statistically adjust those curves to see if age really was a factor or it wasn't.

Dr Ouzounian. Those are good points. In the first decade, some of the Marfan patients had remodeling, but in the later era that stopped, and almost none of the bicuspid valve patients had remodeling because we learned the patients having reimplantation with bicuspid valves come with an aortic root phenotype and they have annuloaortic ectasia; they are in fact quite phenotypically similar to the Marfan patients.

I think the age idea is excellent. We may be a little bit underpowered to stratify that.

Dr Coselli. I know your group saves any valve you possibly can, we get that, but part of the stress on the aortic valve leaflet has to do with the fact that the tricuspid valve can open to the full circumference of the aortic annulus, because if you look at the free edge of the leaflet and the circumference, basically you have got 6 times $R$ and that's what the free edge is. In a bicuspid valve, it is only 4 times $\mathrm{R}$, and that's why on echo we see a fish-mouth opening, and the stress levels on those kinds of leaflets are far different. At 8 years, you are sort of getting to the point almost where if you replaced it just simply with a tissue valve you would begin to start seeing a follow-up. So, we are very much looking forward to the longer-term follow-up.

I know that they are highly selective, but how do they really compare to the patients who underwent just a Bentall operation?

Dr Ouzounian. Of course, they are different patients. We published in JACC last year looking at Bentall with biological or mechanical valves compared with valve-sparing roots and showed what you would expect but improved outcomes following valve-sparing root procedures. But we have been selective. And I think the stresses on the leaflets 
and the root dynamics is an interesting one where we have some 4D flow MRI studies in place right now looking at reimplantation, remodeling in patients with bicuspid and tricuspid valves following valve-sparing root procedures. It is very preliminary, but we are looking forward to sharing those data. 